\title{
Las redes sociales, un nuevo espacio de creación, contacto y desarrollo para las instituciones culturales y sus seguidores
}

Isabel Calvo Bayo | restauradora y conservadora de bienes culturales

URL de la contribución <www.iaph.es/revistaph/index.php/revistaph/article/view/4806>

Adquirir una mayor participación y buena comunicación en el mundo digital se ha convertido hoy en un punto trascendental para las instituciones culturales. Con la era de la digitalización, es un hecho bastante común que millones de personas consulten información cultural mediante Internet, ya sea para escuchar música, conciertos, ver películas, ilustraciones, entre otras prácticas (Chic 2018).

¿Y qué entendemos por cultura en las redes? Este concepto incluye dos acepciones recopiladas por los antropólogos estadounidenses Alfred Kroeber y Clyde Kluckhohn en 1952: una se refiere al gusto por las bellas artes y las humanidades, conocido como "alta cultura", y la otra alude al "conjunto de saberes, creencias y pautas de conducta de un grupo social, incluidos los medios materiales que usan sus miembros para comunicarse entre sí". Asimismo, tal y como afirma el escritor José de la Peña, relacionar la "alta cultura con las tecnologías que usan los seres humanos para intercambiar experiencias es hablar doblemente de cultura". Además, los códigos y comportamientos ligados a la red comienzan a reconocerse como "cultura digital" (De la Peña 2014, 101).

El fácil acceso a internet gracias a la proliferación de dispositivos, como ordenadores, tablets y smartphones, permite la posibilidad de compartir experiencias mediante imágenes, vídeos y textos en tiempo real en redes sociales como Facebook, Twitter e Instagram. Estas aplicaciones proporcionan un punto de encuentro para intercambiar información y opinión de manera bidireccional, suponiendo un cambio sustancial para la sociedad durante las últimas décadas. Así pues, las instituciones culturales han puesto su foco de atención para ofrecer una buena comunicación online. De esta forma, pueden interactuar con sus seguidores, recoger comen-

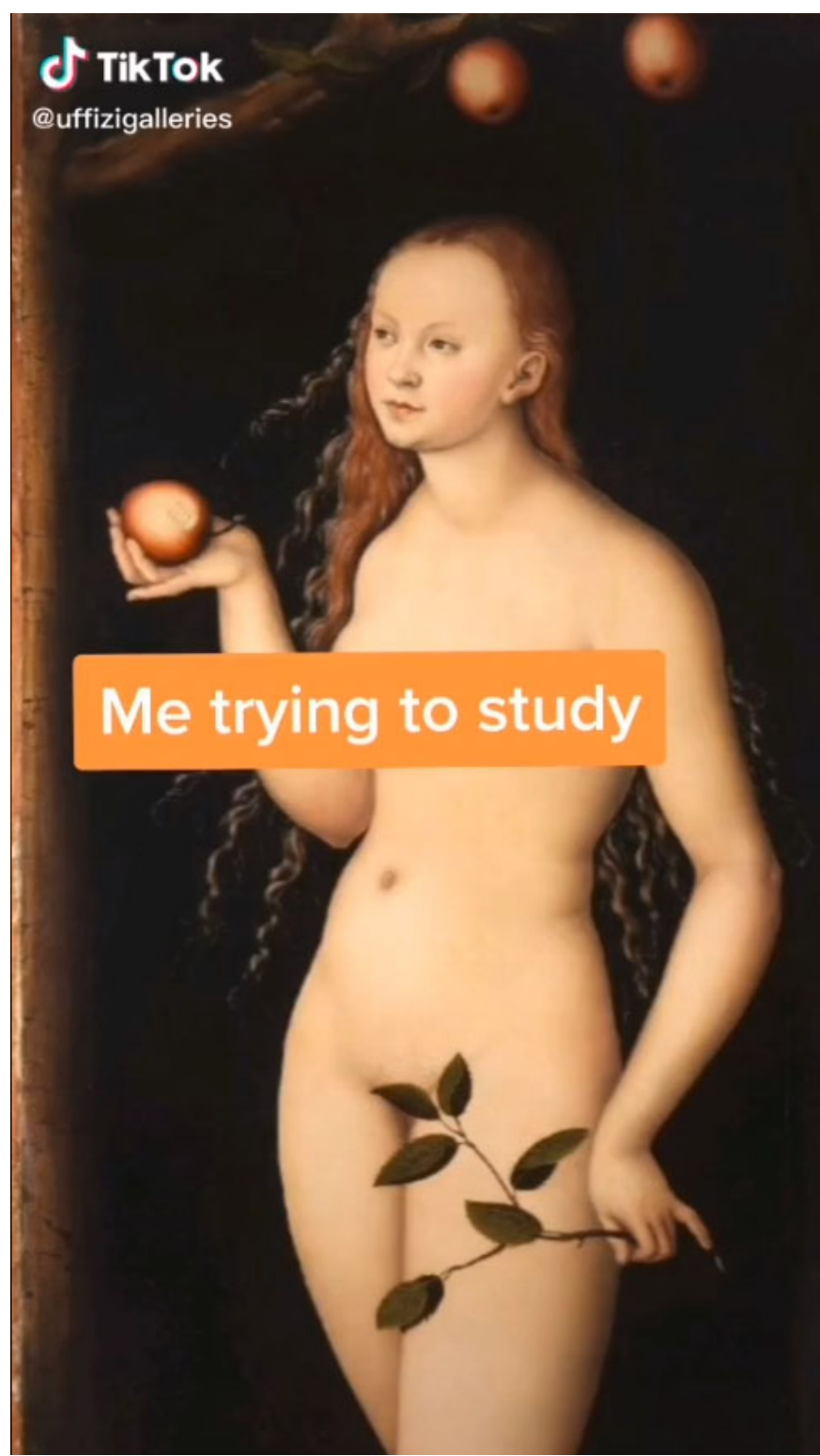

Ejemplo de una de las estrategias de participación en redes sociales de una institución cultural | fuente @uffizigalleries en TikTok 
a debate Comunicación y redes sociales en instituciones culturales

| coordina Candela González Sánchez

tarios para corregir deficiencias, conocer sus gustos y necesidades para obtener informes y estadísticas, y conseguir una oportunidad de expansión y difusión entre un público nuevo y joven que emerge digitalmente.

Por ello, hoy en día numerosas instituciones culturales están presentes en las redes sociales y elaboran procesos de difusión de información entre los usuarios mediante distintos mecanismos. Entre ellos se encuentra la utilización de hashtags, retweets, likes, comentarios y respuestas, junto con las famosas stories. Este conglomerado de métodos ayuda a dinamizar y expandir un contenido entre los usuarios de una comunidad digital, así como fomentar su participación e interacción, favoreciendo la prolongación de la experiencia cultural entre los miembros de una red social.

Entre las distintas estrategias de las instituciones culturales en redes sociales, se puede encontrar la exposición de la colección de un museo, con su explicación y restauraciones mediante tweets o posts, como ha realizado el Museo Thyssen y Rijksmuseum, que poco a poco ha ido ganando divulgación y seguidores. La creación de concursos y sorteos también supone un método eficaz para atraer al público e interaccionar con él, algo que ya realizan la Casa Batlló o el festival Primavera Sound. Asimismo, estas tareas son llevadas a cabo por especialistas en redes sociales, los community managers, que comprenden los códigos y el público para acercarse a él.

También hay que mencionar la fuerte influencia que ejercen las celebrities al añadir contenido cultural en sus creaciones, como ocurre con el álbum del Mal querer de Rosalía, cuyo análisis artístico ha generado debate en las redes, o el vídeo de Beyoncé y Jay Z en el Louvre, que favoreció el incremento de visitantes en el museo durante el año de su lanzamiento. Por otro lado, están los influencers, usuarios con gran cantidad de seguidores, que adquieren una enorme capacidad de atraer nuevas audiencias y promocionar productos (Chic Pujol 2018, 22). Paralelamente, lo que desean las instituciones, al igual que las marcas comerciales, es que los usuarios no sólo sean meros consumidores, sino fans que adoren la

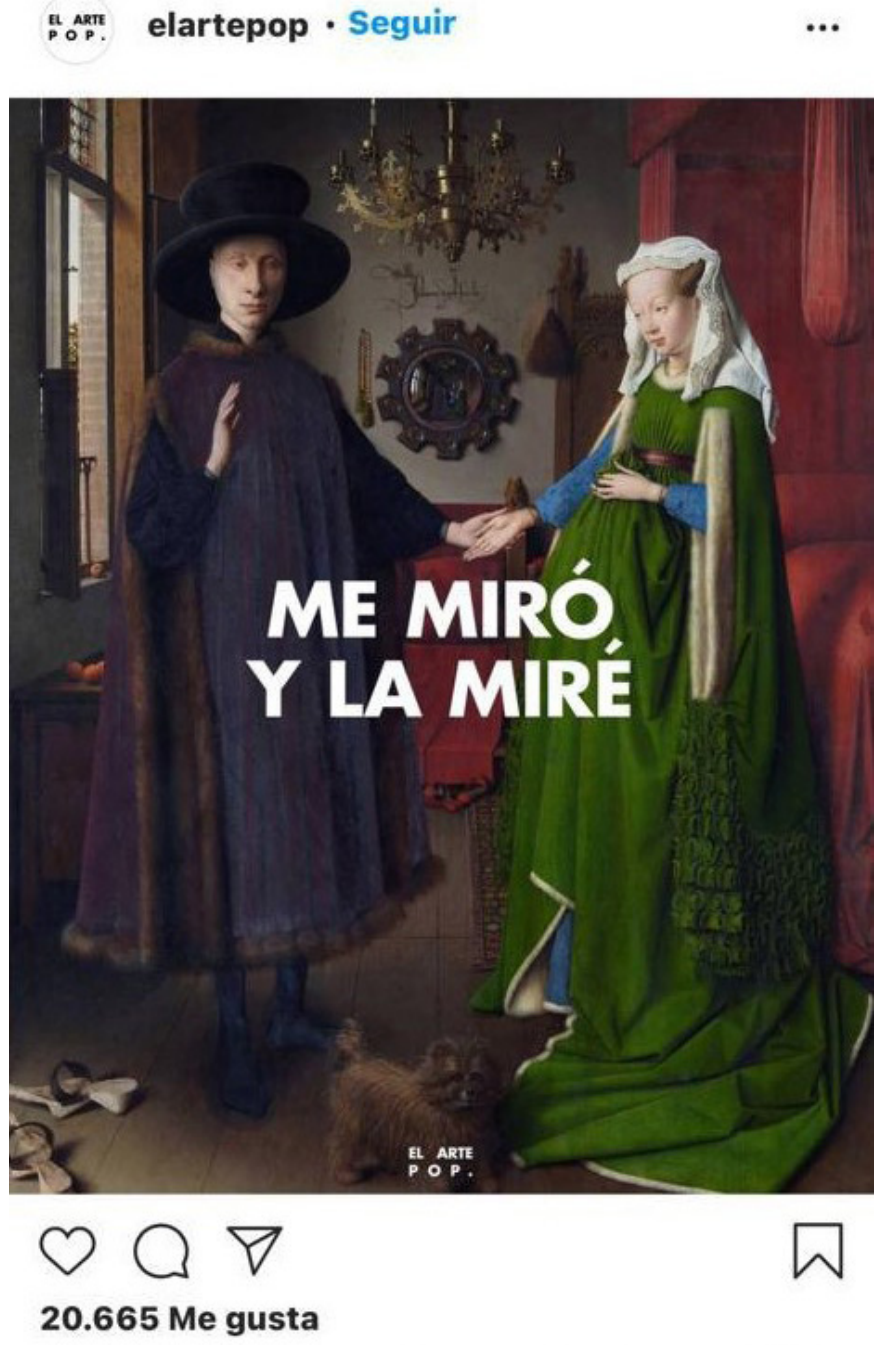

Ejemplo de un proceso creativo para transmitir contenido cultural y alcanzar públicos en redes sociales mediante el uso de una de las frases que compone una canción muy popular entre jóvenes y su relación con una obra artística. Paralelamente, la propia cuenta consigue una oportunidad de negocio, ya que vende merchandising con tales imágenes | fuente @elartepop en Instagram

marca y sean recomendadores de la misma (De la Peña 2014, 102) de esta forma la información es difundida de una manera más eficaz, extensa y económica.

El humor también es un potente vehículo para transmitir información y conseguir viralidad en redes sociales. Un ejemplo de ello lo consiguió la Galería Uffizi, que duplicó los visitantes jóvenes en 2020 tras la interacción de ellos a 
través de su cuenta oficial de TikTok, elaborando memes con las obras clásicas de la colección (Grijota 2020).

Después de la crisis sanitaria acontecida por la COVID19 en 2020, ocasionando confinamientos en toda la población, la cultura ha tomado especial protagonismo en las redes, utilizándose como método de entretenimiento durante la estancia en el hogar. De esta forma, las instituciones culturales han reforzado sus estrategias para ganar relevancia en Internet creando conciertos online, exponiendo colecciones, digitalizando y subiendo archivos como libros, pinacotecas, etc., consiguiendo de esta forma un aumento de sus seguidores durante estos últimos meses.

El Museo de Bellas Artes de Sevilla realizó directos en las redes para mostrar la exposición de Martínez Montañés, que había quedado suspendida. Por otro lado, el Museo de Arte Africano Arellano Alonso de UVA creó una página para favorecer la visita virtual al museo, compaginado con actividades en Youtube y podcasts en Spotify. Otras instituciones con gran actividad digital, como el Museo del Prado o MACBA, solo tuvieron que continuar con su funcionamiento, pero añadiendo nuevas actividades adaptadas a la actualidad, como La Fábrica, que lanzó una convocatoria de fotografías de ventanas y balcones en tiempos de confinamiento.

Por tanto, no hay duda de que la presencia de las instituciones culturales en redes sociales y su posibilidad de feedback con sus usuarios permite un crecimiento cultural con el público. Así lo afirmaba La Institución Museística de Arte Africano Arellano Alonso: "Lo más interesante es que hemos entrado en contacto con personas o colectivos que también trabajan sobre cultura africana y ahora nos hemos conocido. Compartimos contenido y opiniones, se ha creado una red muy interesante y enriquecedora" (Granero Cendón 2020). De modo que el potencial de las redes sociales reside en crear comunidades de interés que promueven la participación y colaboración.

Un ejemplo de una institución que cumple con la mayoría de las estrategias citadas anteriormente es el Museo
Nacional Thyssen-Bornemisza, precursor de actividades que implican a miembros de las redes sociales y merecedor del Premio Europeo Art Explora por su proyecto innovador \#VersionaThyssen para atraer nuevos públicos a los museos.

Finalmente, tampoco se debe de olvidar el tejido no institucional compuesto por proyectos que lanzan entusiastas para compartir información y opiniones. Esto ocurre con numerosas cuentas en redes sociales de cine y música, blogs y foros, junto con aquellas que proporcionan un espacio de creación colectiva. Entre ellas se encuentra el Espacio Artemisa que, a través de su cuenta de Instagram, expone digitalmente las obras de jóvenes artistas. Así pues, se puede afirmar que las redes sociales son generadoras de cultura y hablar de ellas como nuevas instituciones culturales debido al gran contenido que se desenvuelve en ellas.

Como se ha mostrado, las redes sociales suponen un medio para fortalecer la cultura, ya que permiten un espacio para crear, informar, interactuar y perpetuarla. Además, proporcionan un vehículo económico y eficaz para ejercer una de las principales actividades de gestión del patrimonio cultural, que sería su difusión, promoviendo la educación de un público joven, presente mayoritariamente en comunidades digitales.

\section{BIBLIOGRAFÍA}

- Canogar, D. (2020) El Museo del Prado aumentó un 10,7\% las visitas en 2019, y el Reina Sofía subió un 12\%. El Español, 2 de enero de 2020. Disponible en: https://www.elespanol.com/ cultura/arte/20200102/museo-prado-aumento-visitas-reinasofia-subio/456704872_0.html [Consulta: 04/12/2020]

- Chic Pujol, L. (2018) Los principales retos de las instituciones culturales con la comunicación online en la revolución 2.0. Culturas. Revista de Gestión Cultural, vol. 5, pp. 20-28. Disponible en: https://polipapers.upv.es/index.php/cs/article/ view/10793 [Consulta: 26/11/2020]

- De la Peña Aznar, J. (2014) ¿Sirven para algo las redes sociales en el sector cultural? En: Anuario AC/E de cultura digital 2014, pp. 101-112. Disponible en: https://www. accioncultural.es/media/Default\%20Files/activ/2014/Adj/ Anuario_ACE_2014/8RedesSociales_JPen\%CC\%83a.pdf 


\author{
a debate Comunicación y redes sociales en instituciones culturales \\ | coordina Candela González Sánchez
}

[Consulta: 16/12/2020]

- Díaz Pérez, F., Martínez Solís, L. y Chaín Navarro, C. (2019) Difusión patrimonial en la web: herramienta de análisis para instituciones culturales. Revista General de Información y Documentación, vol. 29, n. ${ }^{\circ} 2$, pp. 349-375. Disponible en: https://revistas.ucm.es/index.php/RGID/article/view/66972 [Consulta: 28/11/2020]

- Granero Cendón, J. I. (2020) La comunicación de las instituciones culturales en tiempos de coronavirus. La cultura social, 9 de abril de 2020. Disponible en: http://laculturasocial. es/la-comunicacion-de-las-instituciones-culturales-entiempos-de-coronavirus/ [Consulta: 02/12/2020]

- Grijota, E. (2020) Adiós academia, hola TikTok: la estrategia sin complejos con la que la Galería Uffizi ha duplicado los visitantes jóvenes en tres meses. El País, 19 de octubre de 2020. Disponible en: https://elpais.com/icon-design/2020-10-18/ adios-academia-hola-tiktok-la-estrategia-sin-complejos-conla-que-la-galeria-uffizi-ha-duplicado-los-visitantes-jovenes-entres-meses.html [Consulta: 23/11/2020]

- Laguna, C. (2020) El Museo del Prado o la cuenta de TikTok en la que triunfan Goya y Velázquez. Condé Nast Traveler, 29 de septiembre de 2020. Disponible en: https://www.traveler. es/experiencias/articulos/museo-del-prado-cuenta-tiktok-exitoredes/19186 [Consulta: 03/12/2020]

- Moreno Cámara, A. y Prieto Gutiérrez, J. J. (2011) Instituciones culturales en un click. Razón y palabra, n. ${ }^{\circ}$ 78. Disponible en: http://www.razonypalabra.org.mx/varia/N78/2a\%20parte/25_ MorenoPrieto_V78.pdf [Consulta: 02/12/2020]

- Museo Thyssen (2020) Art Explora da a conocer a los 3 ganadores de la primera edición del premio europeo Art Explora-Academia de Bellas Artes. 3 de diciembre de 2020. Disponible en: https://www.museothyssen.org/prensa/notasprensa/art-explora-da-conocer-3-ganadores-primera-edicionpremio-europeo-art-explora [Consulta: 07/12/2020]

- PHotoEspaña (2020) "No importa que cierren las puertas, entraremos por el balcón". Convocatoria online \#PHEdesdemibalcón. PHotoESPAÑA. Disponible en: https:// www. phe.es/phe-20/proyectos-digitales/convocatoria-onlinephedesdemibalcon/ [Consulta: 01/12/2020]

- Primavera Sound (2020) Bases Legales \#PrimaveraSoundChallenge. Disponible en: https://www. primaverasound.com/es/home/terms-and-conditions-forprimavera-sound-challenge [Consulta: 03/12/2020]

- Sanjuán Ballano, B. (2008) Información=Cultura. Mapas patrimonialespara ir de los medios a las mediaciones. En: Sanjuán Ballano, B. (coord.) Patrimonio cultural y medios de comunicación. Sevilla: Instituto Andaluz del Patrimonio Histórico, Consejería de Cultura, pp. 30-44 (PH cuadernos, 21) 